\title{
Novos Rumos para o Processo de Avaliar: desafios para os professores do Ensino Fundamental $^{*}$
}

\author{
LINA CARDOSO NUNES \\ Doutora em Educação/UFRJ. Pesquisadora e professora do Mestrado em Educação \\ da Universidade Estácio de Sá \\ linanunes@ig.com.br
}

\begin{abstract}
Resumo
Este artigo relata o breve estudo que teve como objetivos, inicialmente, analisar as relações entre avaliação e aprendizagem dos conteúdos sistemáticos propostos pela escola, identificando como a forma de avaliar e/ou os procedimentos de avaliação podem influenciar no processo de desenvolvimento e aprendizagem dos alunos avaliados. Posteriormente buscou-se analisar as modalidades de avaliação implementadas no Ensino Fundamental no contexto dos Parâmetros Curriculares Nacionais - PCNs, explicitando a sua contribuição para o desenvolvimento da autonomia do sujeito. A investigação foi realizada em quatro escolas públicas do município do Rio de Janeiro e teve como principais conclusões que há um empenho indiscutível da direção para o êxito das atividades que são desenvolvidas com seriedade e respeito pela equipe de professores e embora se observe, em diferentes momentos, os entraves para a realização das propostas oficiais, já se pode reconhecer que novos rumos para o processo de avaliar se instituem progressivamente.

Palavras-chave: avaliação, aprendizagem, autonomia, Parâmetros Curriculares Nacionais.
\end{abstract}

\section{Resumen}

Este trabajo relata el breve estudio que tiene por objetivos, inicialmente, analizar las relaciones entre evaluación y aprendizado de los contenidos sistemáticos propuestos por la escuela, identificando como la forma de evaluar e/o los procedimientos de evaluación, pueden influenciar en el proceso de desenvolvimiento y aprendizado de los alumnos evaluados. Posteriormente, fueron analizadas las modalidades de evaluación aplicados en la Enseñanza Básica en el contexto de los Parámetros Curriculares Nacionales - PCNs, destacando su contribución para el desenvolvimiento de la autonomía del sujeto. La investigación fue realizada en cuatro escuelas publicas del municipio de Rio de Janeiro y como principal conclusión se verifica que existe un empeño indiscutible de la dirección para el éxito de las actividades que son desenvolvidas con seriedad y respeto por el equipo de profesores $\mathrm{y}$, aunque se observen en diferentes momentos algunos obstáculos para la

\footnotetext{
* A pesquisa relatada no presente artigo foi realizada com o apoio financeiro do CNPQ/UNESA e contou com a colaboração de quatro bolsistas no decorrer do processo: Maria Luiza Garro, Danielle Castellões, Amanda Dayube e Ana Kliscia da Silva Reis.
} 
realización de las propuestas oficiales, ya se pueden vislumbrar la institución gradual de nuevos rumbos para el proceso de evaluar.

Palabras-clave: evaluación, aprendizado, autonomía, Parámetros Curriculares Nacionales.

\begin{abstract}
This article reports on a brief study which initially aimed at analyzing the relationship between assessment and learning the systematic contents proposed by the school. This was done by identifying how the assessment and/or the assessment procedures may influence the students' process of development and learning. Later the assessment modalities put into operation at the Ensino Fundamental (grades 1 through 8) within the context of the National Curriculum Parameters - PCNs - were analyzed bringing to the fore their contribution to the development of the students' autonomy. The investigation was conducted in four public schools in the Rio de Janeiro municipality and its main conclusions revealed an indisputable effort by the management toward the success of activities carried out in seriousness and respectful of the team of teachers. Although, at times, some obstacles have been observed, it was nevertheless possible to realize that new directions in the assessment process are already being progressively established.

Key words: evaluation, learning, autonomy, Parâmetros Curriculares Nacionais.
\end{abstract}




\section{APRESENTAÇÃO DA PESQUISA}

A práxis avaliativa tem sido objeto de estudos sistemáticos de educadores, revelando aspectos contraditórios no processo de avaliar, representados por ambigüidades e conflitos emergentes na observação das práticas institucionais vivenciadas nas escolas. Essas práticas remetem à realidade social, configurada por uma luta hegemônica, que reproduz as "desigualdades, tensões e possibilidades sociais" (Esteban, 2001, p.25).

Em estudos e pesquisas realizados no âmbito nacional aparecem questões críticas que têm preocupado os envolvidos com a escola, tais como a evasão e a repetência, alertando para o fracasso escolar, especialmente nas classes populares. Nesse contexto, essa problemática é debatida em congressos, seminários e encontros que congregam especialistas e professores, indicando possíveis soluções para enfrentar o afastamento de grande número de crianças das salas de aula e/ou a permanência de outras que, embora matriculadas na escola, estão excluídas do processo de aprendizagem. Este fato aponta para a questão da dissociação entre os processos de ensinar e aprender e o de avaliar.

A leitura e análise do tema "fracasso escolar" (Patto, 1993), em sua dimensão social, possibilitou entender, numa perspectiva histórica, a questão dos que fracassam na escola. De acordo com Patto (1993, p. 21), a pesquisa histórica revela que uma política educacional, em seu sentido estrito, tem início no séc. XIX (...) Essa política educacional teve origem em três vertentes: a visão de mundo dominante na nova ordem social, de um lado, a crença no poder da ciência e da razão, de outro, o projeto liberal, apontando para um mundo com igualdade de oportunidades e, a última, a luta pela consolidação dos estados nacionais que impregnou a vida política do século passado.

Esta vertente nacionalista parece ter sido a principal estimuladora de uma política ofensiva de implantação de redes públicas de ensino em algumas partes da Europa e na América do Norte e, posteriormente, no Brasil.

Uma das alternativas para superação da evasão, da repetência e da exclusão foi a implantação, nas escolas, dos ciclos de aprendizagem que têm como principal objetivo "tornar as progressões mais fluidas, abolindo ou limitando a repetência" (Perrenoud, 1999, p.8), fenômeno que traz aos alunos e professores desafios, tanto na dimensão pedagógica, quanto na dimensão sociocultural e afetivo-emocional.

Sob tal ótica "a organização da escola em ciclos de aprendizagem, principalmente a primária, está sendo discutida em vários países desenvolvidos. Em alguns sistemas ela já foi adotada no papel, mas sua 
implementação tem sido apenas parcial" (Perrenoud, 1999, p.8). Assim como a proposta de ciclos escolares, as classes de aceleração têm sido anunciadas como alternativa para a superação dos problemas de repetência e/ou evasão, que freqüentemente resultam na exclusão da criança e do jovem e, em alguns casos, remetem ao fracasso escolar. Nesse contexto, o processo de avaliar apresenta possibilidades de atender mais efetivamente à diversidade dos alunos e as suas dificuldades. Como outras propostas inovadoras, essas também têm sido recebidas com alguma desconfiança pelas comunidades escolares.

Alguns aspectos das citadas alternativas - a implementação dos ciclos de aprendizagem e das classes de aceleração - apresentam convergências que apontam para as competências dos professores, entre as quais, a necessidade de organizar e animar situações de aprendizagem, administrar o progresso do que os alunos aprendem, estimular o compromisso dos alunos com a própria aprendizagem e dinamizar o trabalho em equipe (Perrenoud, 1999).

Tanto na implementação dos ciclos escolares quanto das classes de aceleração, a construção de competências no bojo da formação continuada do professor evidencia-se como um dos pontos focais. Emergem idéias já discutidas pelos educadores, mas não concretizadas, em algumas oportunidades, pela insuficiência de preparação do professor, diante da multiplicidade de procedimentos a serem organizados e da necessidade de infra-estrutura material das escolas. Nesse sentido, torna-se praticamente impossível viabilizar propostas inovadoras, independentemente do contexto nas quais estão inseridas, pois é indispensável o gerenciamento das ações e decisões, na comunidade escolar, que permitirão aos professores a apropriação das competências a serem desenvolvidas.

$\mathrm{Na}$ implementação das inovações que se multiplicam nas escolas, o processo de avaliação tem se constituído em um desafio para o professor de Educação Básica, apontando novos rumos para o processo de avaliação. As mudanças, tanto da proposta da Multieducação da Secretaria Municipal de Educação do Rio de Janeiro (1995) quanto as relativas à aplicação das diretrizes indicadas pelos Parâmetros Curriculares Nacionais (PCNs, 2000), e no que tange ao processo de avaliar, têm gerado discussões entre diretores, coordenadores pedagógicos e professores, apresentando aspectos polêmicos, especialmente no que se refere à operacionalização das modalidades de avaliar no Ensino Fundamental apontadas nos documentos oficiais.

O processo de avaliar é vivenciado nas classes e envolve o professor que ensina e o aluno que aprende. As modalidades de avaliar aplicadas pelos professores poderiam contribuir para o desenvolvimento da 
autonomia do sujeito avaliado. Entretanto, tem se observado, na prática escolar, que essas modalidades não são operacionalizadas no sentido da autonomia dos aprendentes, mas remetem, em alguns casos, a formas contraditórias, como a utilização de instrumentos padronizados, por meio dos quais os alunos respondem o que foi transmitido pelo professor, reproduzindo os conteúdos definidos como certo e errado.

Segundo Esteban (2001, p. 58) "a presença do erro, mais que do acerto, coloca em discussão a prática pedagógica". Nesse contexto, a ação de avaliar tem sido norteada, freqüentemente, com relação a erros dos alunos não considerados no percurso do processo de aprendizagem como possibilidade de construção do conhecimento, reproduzindo ainda a idéia de aprendizagem dissociada da avaliação. As práticas pedagógicas deveriam integrar os processos de ensinar, aprender e avaliar, constituindo-se como favorecedoras do desenvolvimento de alunos autônomos e criativos.

Nessa linha de raciocínio, Fernandez (1990) alerta para as causas do fracasso escolar, no contexto da dimensão afetivo-emocional, ligadas à estrutura individual e familiar da criança. Segundo ele, "o problema de aprendizagem, que constitui um sintoma ou uma inibição, afeta a dinâmica da articulação entre os níveis de inteligência, o desejo, o organismo e o corpo" (p.82) e tem como conseqüência um aprisionamento da inteligência. Já o problema reativo de aprendizagem, ao contrário, "afeta o aprender o sujeito em suas manifestações", surgindo "a partir do choque entre o aprendente e a instituição educativa" (p. 82). Pode-se compreender que, nesses casos, os alunos, com certa freqüência, perdem o entusiasmo pelas atividades escolares e se desinteressam, considerando-se incapazes de aprender.

Freire afirma que se deve

respeitar a autonomia, a identidade, a dignidade do educando e na prática procurar coerência com este saber (...). Essa atitude, segundo o autor, "leva inapelavelmente à criação de algumas virtudes ou qualidades sem as quais aquele saber vira inautêntico, palavreado, vazio e inoperante. (2000, p 69)

O respeito à autonomia do indivíduo, segundo Freire, está intimamente relacionado com a coerência e bom senso, ultrapassando as barreiras da teoria em busca da prática pedagógica, pautados em virtudes e qualidades éticas.

Sob tal ótica, ninguém é autônomo primeiro para depois decidir. A autonomia vai se construindo na experiência de várias e inúmeras decisões, que vão sendo tomadas (Freire, 2000, p.120). Ressalta-se, ainda, a autonomia como algo que irá ser construído de acordo com as decisões e experiências 
individuais. Partindo de princípios norteadores do respeito e da necessidade de formar educandos autônomos é de suma importância refletir: como seriam realizadas avaliações decorrentes desta prática pedagógica?

No contexto da multiplicidade de questões emergentes sobre o processo de avaliar, a pesquisa descrita nesse artigo, constituiu-se em duas etapas. Na primeira, objetivou-se: (a) analisar, pela fala dos professores, as relações entre avaliação e aprendizagem dos conteúdos sistemáticos propostos pela escola; e (b) identificar como a forma de avaliar e/ou os procedimentos de avaliação podem influenciar no processo de desenvolvimento e aprendizagem do sujeito. $\mathrm{Na}$ segunda etapa, os seguintes objetivos foram delineados: (a) analisar as modalidades de avaliação implementadas no Ensino Fundamental no contexto dos Parâmetros Curriculares Nacionais - PCNs; e (b) explicitar a contribuição das modalidades de avaliar do Ensino Fundamental para o desenvolvimento da autonomia do sujeito.

\section{TRAJETÓRIA DA PESQUISA}

A presente investigação realizou-se em duas etapas em quatro escolas da zona norte do município do Rio de Janeiro denominadas, neste relato, A, B, C e D. Utilizaram-se como instrumentos roteiros de observação - um destinado às reuniões de professores e outro para as turmas de alunos - e roteiros de entrevistas individuais e coletivas para professores e alunos, de acordo com os objetivos do estudo, em cada etapa. Participaram do estudo, nas duas etapas da pesquisa, três coordenadores, vinte e cinco professores, quarenta e três alunos de duas turmas de quarta séries, vinte e cinco alunos de ciclos escolares, e trinta e um alunos de classes de aceleração, num total de cento e vinte sete participantes.

A primeira etapa da pesquisa ocorreu nas escolas A, B e C, e enfocou a forma como os professores de educação básica vêem as relações entre a aprendizagem e a avaliação.

Inicialmente, fizeram-se os primeiros contatos com as escolas por intermédio da Secretaria Municipal de Educação e da CRE. Pode-se assinalar que, nas escolas para as quais fomos encaminhados, a equipe foi muito bem recebida, conforme depoimentos das bolsistas. Apresentamos o projeto às escolas e pudemos, imediatamente, marcar os primeiros encontros com os professores, com o aval das diretoras de duas escolas. Atendemos aos horários marcados pela direção das escolas que se dispuseram a nos receber. Foi possível, nesta etapa da pesquisa de campo, 
realizar 11 (onze) entrevistas com os professores de duas escolas - A e B nas quais se iniciou o estudo.

Posteriormente, foi viabilizado o contato com a escola na qual ainda não havia sido realizada a investigação. A diretora demonstrou, verbalmente, sua aceitação ao projeto que foi deixado para leitura e apreciação. Foi solicitado que participássemos de reuniões, nas quais apresentaríamos o projeto e definiríamos as datas para entrevistar os professores.

Por razões explicitadas posteriormente pela direção da escola relativas à dupla jornada de trabalho, tendo em vista os projetos oficiais da Secretaria Municipal de Educação em andamento, não houve tempo hábil para a realização das entrevistas na escola C; assim, optou-se pela entrega de um questionário com questões abertas para ser respondido pelos professores. Tivemos oportunidade de voltar à escola para participar dos Conselhos de Classe. Os instrumentos respondidos foram devolvidos pela coordenação; a bolsista responsável, nessa etapa do processo, fez a transcrição e, posteriormente, de modo participativo, com a coordenadora da pesquisa, foi feita a análise e interpretação dos dados coletados, tanto do conteúdo das entrevistas, quanto das reuniões das quais participamos e dos depoimentos dos professores.

\section{Análise e interpretação dos dados da primeira etapa da pesquisa}

Inicialmente realizou-se a transcrição das entrevistas feitas nas escolas A e B pela bolsista, o que viabilizou a análise dos dados coletados. Procedeu-se à leitura exaustiva das entrevistas, inicialmente pela busca de palavras usadas sistematicamente, frases repetidas nas falas dos entrevistados e categorização dos temas emergentes.

Foram identificados os seguintes temas: (a) situações familiares e aprendizagem; (b) aspectos socioeconômicos e dificuldades dos alunos; (c) desinteresse e dificuldades de aprendizagem; (d) relações entre conteúdos e o processo de aprender; (e) dificuldades para definir formas de avaliação e (f) processo de aprendizagem e a avaliação. Cada um dos temas foi separado nas falas dos professores, procurando relacioná-los com aspectos teóricos considerados significativos para o tema investigado.

Situações familiares e aprendizagem

As falas dos professores, ao serem perguntados sobre as causas que facilitam ou dificultam a aprendizagem, freqüentemente apontaram para 
problemas ligados a situações familiares problemáticas, como pode ser visto nas falas transcritas a seguir:

C - Nossos alunos dificilmente passam por períodos de estímulos em casa.

G - Há problemas sérios com a família, não há interesse por parte dos pais (...) a mãe é desinteressada e não acompanha os filhos, os pais são analfabetos.

F- Há falta de interesse dos pais em acompanhar e valorizar a produção/aprendizagem dos filhos.

Essas falas apontam para as mesmas causas indicadas por Fernandez (1990) para o fracasso escolar, visto que abordam primeiro a estrutura familiar e individual sob o efeito de causas externas (reativo), em seguida mostram o efeito de causas internas (sintoma e inibição). Pode-se interpretar que os professores, em suas falas, atribuem o fracasso da criança na escola a questões desfavoráveis de ordem familiar: alcoolismo, desinteresse dos pais, analfabetismo, entre outros citados.

\section{Aspectos socioeconômicos e dificuldades dos alunos}

$\mathrm{Na}$ perspectiva dos professores foram também apontadas as questões ligadas a aspectos sociais e financeiros como fatores que podem trazer dificuldades para os alunos; em várias falas aparecem palavras e/ou expressões, como pobreza, baixa renda, necessidade de comida, problemas na comunidade em que residem, sinalizando para o contexto socioeconômico das crianças. A forma como os professores se expressam pode ser interpretada como a idéia que fazem da relação entre as dificuldades apresentadas e as condições como os alunos chegam à escola, com um mínimo de possibilidades de participar efetivamente das atividades. Adiante aponta-se a maneira como os professores falaram sobre o tema:

C - Nossos pais têm situaçães econômicas e de relação familiar sem estrutura que viabilize a visão e o tempo para o tão necessário desenvolvimento.

G - Problemas sérios com a família e pobreza (...) baixa renda familiar, as crianças trabalham em casa e chegam aqui brincam, vêm ser crianças, não cobro, não ganho nada com isso, em cobrar, não é? Eles vêm para cá, porque é um lugar em que podem se alimentar e brincar, estragam tudo...

Patto (1993, p.125) assim se refere ao conhecimento que os professores têm sobre a questão social de seus alunos: "o desconhecimento a respeito dessas crianças é generalizado e está presente também no corpo do conhecimento científico; portanto mesmo que o professor tente (...) 
corrigir seus vieses (...) é provável que continuará a desconhecer seus alunos, julgando que os conhece".

\section{O desinteresse e as dificuldades de aprendizagem}

Um dos temas mais enfatizados na fala dos professores foi o relacionado ao desinteresse e às dificuldades de aprendizagem do aluno da escola básica. Neste aspecto percebe-se a articulação entre as questões familiares e socioeconômicas. O desinteresse também aparece relacionado a aspectos dos conteúdos escolares, que nem sempre resgatam os valores da comunidade onde as crianças residem. Sob tal ótica, as idéias de Forquin (1993) e a proposta da Multieducação (Rio de Janeiro, 1995) explicitam a necessidade de reverter a situação escolar, tendo em vista a valorização dos conteúdos programáticos integrados à vida infantil.

A seguir, é possível rever as falas dos professores que enfatizam esse tema:

A - ...falta interesse, auto-estima baixa, falta de interesse dos pais (...)

I - Não há interesse por parte dos pais; é muito difícil a criança nessa situação toda, você, professora, perde o interesse e o aluno também; a mãe é desinteressada. Trago os brinquedos da minha filha e eles ficam mais interessados.

$\mathrm{J}$ - O aluno não tem interesse, eles sabem que vão passar. Não há consciência de que o estudo é importante.

$\mathrm{K}$ - Esse ano tenho uma turma muito desinteressada. (...) se eu começo um assunto de interesse, namoro, por exemplo, eles falam um pouco e dizem: Vamos logo, passa um trabalho aí, como se eles tivessem algo importante a fazer e tivessem que terminar logo a aula (...).

Dificuldades de definir formas de avaliação

As dificuldades para o professor avaliar ficam implícitas nas falas dos professores que parecem, também, não ter certeza de como devem avaliar seus alunos. Não consideram a prova como a melhor forma de avaliação, mas não apontam, concretamente, sua prática de como deva ser a avaliação.

A - ...não vejo o instrumento prova/teste como prioridade.

$\mathrm{J}$ - A prova é um documento. Eles não querem prova, mas se você reprova eles querem o documento. Eles gostam de livros, gostam de provas. Eles sentem necessidade de avaliação, a prova não pode ser negada. Deixar o aluno suando não, mas ele precisa ser testado; a vida é assim, para tudo se faz prova. 
$\mathrm{K}$ - Eu dei prova. O construtivismo diz para não dar prova, ô caramba, pois se na vida tem que fazer prova...

Percebe-se nas falas dos professores que a prova é vista como um fetiche, como é mostrada por Luckesi (1996) no contexto da "Pedagogia do Exame". "Ao longo da história da educação moderna (...), a avaliação da aprendizagem por meio de exames e provas foi se tornando um fetiche. (...) entidade criada pelo ser humano para atender a uma necessidade, mas que se torna independente dele e o domina, universalizando-se" (p. 230). Embora o professor já não se sinta inteiramente seguro, aplicando provas e dando notas, assumir uma nova postura ainda apresenta dificuldades para o cotidiano do processo avaliativo.

Processo de aprendizagem e avaliação

Os professores entrevistados se expressaram, relacionando a aprendizagem com a avaliação, nas falas transcritas a seguir:

B - O processo de aprendizagem do aluno deve ser de acordo com seu ritmo de aceitação e entendimento; a avaliação vai sendo constante, cumulativa, envolve toda a aprendizagem e faz com que o processo funcione gradativamente, à medida que o aluno entende e percebe ao seu redor.

$\mathrm{H}-\mathrm{A}$ avaliação deve ser contínua, diária, para que o processo ensinoaprendizagem se efetive de forma concreta, mudando sempre que for necessário.

C-A avaliação é feita diária, constante, assim também se processa a aprendizagem que a meu ver não é só de conteúdo (...) o ensino é seqüencial, com conteúdos que dependem da pré-aprendizagem, isto é, a cada série, novos conteúdos são acrescentados aos anteriores (base) e a aprendizagem desses conteúdos depende também de uma série de fatores que se precisa conhecer para fazer uma avaliação justa.

Na visão do professor suas falas confirmam o que é preconizado no documento introdutório dos PCNs (2000) relativo à integração entre aprendizagem e avaliação e, especialmente, se o ensino "cumpriu sua finalidade: a de fazer aprender" (p. 84).

Pode-se interpretar, pelas falas dos professores, que já há, de início, consciência das relações que devem emergir do processo de ensinar e aprender e do processo de avaliar; quando o professor avalia seu objetivo é verificar se as atividades, os conteúdos foram apropriados pelos alunos e se constatar que isto não ocorreu cabe retornar e investigar as causas da defasagem entre o que foi ensinado e o que foi aprendido. 
Nesse sentido, pôde-se observar que as falas dos professores, em relação à avaliação, apontam para uma visão voltada para a continuidade do processo, como pode ser interpretado nas expressões que seguem:

A - Através da observação diária (...). Ela é feita diária e constantemente, assim também se processa a aprendizagem. Ela é feita diariamente com observações.

B - Em todos os momentos dentro e fora da sala de aula (...). A avaliação está praticamente, totalmente ligada no dia-a-dia da escola (...). O aluno não aprendeu nada, porém seus trabalhos de criatividade são interessantes. Este aluno no todo vai ser avaliado diferente dos outros.

E - Tento avaliar por tudo, observação, comprometimentos, rendimento, trabalho de casa, um mínimo ele tem que apresentar.

De forma geral, os professores expressaram, por meio de suas falas, uma visão que aponta para uma abordagem da avaliação como um processo global, cumulativo, conforme as orientações dos PCNs (2000). A avaliação investiga o processo de desenvolvimento do aluno numa perspectiva integral, considerando todos os aspectos apresentados pelos alunos, não se vinculando a um simples procedimento de mensuração.

As falas transcritas possibilitam interpretar que os professores não são favoráveis a instrumentos de natureza quantitativa, mas valorizam as atividades em sala de aula e a observação diária. Nesse sentido atuam, de acordo com suas falas, observando os princípios definidos pelo documento da Multieducação, embora possa ser apontado que, em algumas respostas, ainda há dúvidas quanto a formas de avaliar, no contexto do cotidiano do professor, atendendo à abordagem proposta pela S.M.E.

Ainda nessa etapa, com relação às escolas investigadas e analisando os depoimentos coletados na escola $\mathrm{C}$, em reuniões de professores e naquelas das quais participávamos, alguns aspectos que foram interpretados remetem aos temas levantados inicialmente pelas entrevistas nas escolas A e B, como, por exemplo, a questão do contexto familiar e as alterações da aprendizagem, conforme pode-se constatar nas falas a seguir:

P1 - Eu também acho que posso falar porque conheço as duas realidades. O pai da escola particular é o mesmo da escola pública, mas há o nosso desleixo... As mães da escola pública deixam as crianças sozinhas... Agora na escola particular o professor é mais cobrado.

P2-Acho que o problema é de casa... Eu trabalho na escola pública e na particular, na escola pública na hora de ler e escrever... nada... Eu queria que ele aprendesse a ler. Por que ele não aprende? Acho que é problema de casa (...) na escola particular as crianças são mais saudáveis. Eu trabalhei com o mesmo método na escola particular e na escola pública e na escola particular 
eles aprenderam e na escola pública é um inferno! As crianças têm problemas sérios.

P3 - O D. está em EP, o F. mandei chamar a mãe. Ela trabalha no salão, pedi que a irmã ajudasse em casa. Ele não está vindo nem à sala de leitura.

As falas transcritas evidenciam as relações entre as questões do contexto familiar e a aprendizagem. Percebe-se que os professores e a direção entendem que a presença e o apoio da família, durante o processo de aprendizagem, é importante para os alunos. As falas de P2 e de P1 apontam para as diferenças entre a escola pública e a particular e consideram que o professor da escola particular dá mais apoio. Essas são opiniões isoladas de duas professoras e não podem ser generalizadas, nem é possível tirar conclusões, tendo por base exclusivamente as duas falas. No entanto, a expressão do sentimento de diferença entre escola pública e particular é significativa, nos depoimentos citados.

A respeito das relações entre o contexto familiar e a escola, que é o lugar onde a criança vai para apropriar-se do conhecimento, Perrenoud (1998) afirma que, exceto algumas circulares e episódicas reuniões de pais, "a avaliação é o vínculo mais constante entre a escola e a família" (p.147). Perrenoud explica que a avaliação é uma forma que pode tranqüilizar os pais sobre as possibilidades dos filhos alcançarem êxito em suas ações futuras; na escola isso se viabiliza pela presença dos pais para assinarem os boletins, tomando conhecimento do progresso de seu filho.

Durante uma das reuniões mencionadas anteriormente, uma das questões enfatizadas pelos participantes e também pela representante da CRE foi a necessidade de estímulo para os alunos, a fim de que seu interesse seja despertado, possibilitando participação efetiva nas atividades propostas pelo professor. Esse tema relaciona-se estritamente com o colocado anteriormente durante as entrevistas com os professores sobre a falta de interesse e as alterações de aprendizagem. Fica evidente, nas falas transcritas a seguir, a relação apontada:

P2 - Nós queríamos saber como poderíamos ajudar os alunos que tinham mais dificuldades. Era importante que houvesse uma ajuda para superar seus problemas. Tivemos a oportunidade de dar uma ajuda aos alunos...eles falam muito, têm problemas de rejeição. Percebemos uma coisa interessante. Você elogia muito e eles começam a ficar interessados e querem mostrar à professora do que são capazes. (...) A parte de desenvolvimento da leitura e da escrita eles estão motivados. A história da lagartixa e do jacaré a gente conta muito. Eles têm 16 anos, mas ficam maravilhados. Estão melhorando. O F. diz para mim: você é mãezona.

Representante da CRE - Há necessidade de estimular os alunos. 
P3 - Eles não têm hábitos. Combinamos que colocaríamos as palavras no quadro. É um jogo. Depois eu vou ditar as palavras com o apoio do quadro para ver quem acertou tudo. Muitos acertaram. Teve um que disse: "Nunca acertei o ditado todo, tia". Estamos reforçando o que eles já sabem.

Outro aspecto significativo constatado nas falas dos professores das escolas $\mathrm{A}$ e $\mathrm{B}$ também foi apontado na escolas $\mathrm{C}$. Foi o relacionado às dificuldades para definir os critérios de avaliar, mostrando aspectos contraditórios para a prática do professor. Nos depoimentos abaixo evidencia-se essa preocupação:

P7 - Há dificuldades de definir critérios de avaliação. É preciso dar tempo para o professor se reciclar. Não há situalização; precisa tempo para trabalhar cada etapa.

P8 - Essa modalidade de avaliação caiu de pára-quedas no município, de forma inesperada, falta preparação do professor, precisa aulas mais práticas.

P9 - Não houve consulta aos professores; a dificuldade é definir critérios.

Representante da CRE - Os critérios de aprovação tem que ser fechados. Cada escola tem um critério diferente. Em algumas escolas se a criança sabe escrever o nome é alfabetizada.

Nesse sentido, ratificando a necessidade vista pelos professores de serem preparados para a mudança de modelos de avaliação, Perrenoud (1998, p. 152) afirma que "Esses modos de funcionamento exigem uma nova concepção de equidade e igualdade diante do sistema, uma certa tolerância à desordem e à diferença, capacidade de auto-regulação e de auto-avaliação de uns e de outros". Cada mudança mobiliza as pessoas que dela participam, o que pode configurar, em alguns casos, atitudes de resistência do professor e, em outros, desafios a serem superados em direção às mudanças.

Emergiram falas durante as reuniões de professores que apontaram para a questão da importância da afetividade em relação aos alunos que não são considerados bem-sucedidos na escola e que adquirem uma postura de baixa auto-estima, configurando problemas de falta de interesse nas aulas, tendo como conseqüência atitudes de indiferença, apatia e até indisciplina. Alguns professores expressaram-se nesse sentido, conforme pode ser constatado nas falas a seguir:

P3 - Ficamos preocupadas com a aparência dos alunos. Sou meio carinhosa. Eu abraço, eu beijo (...) Enfatizo a afetividade (...) O P. é extremamente carente. Chamei-o e ele chorou muito. Se o colega estiver incomodando, mudo o lugar. Quando vamos detectando alguma crise, trabalhamos a questão... Por exemplo : o P. falou: "Eu não gosto de morar nas favelas". Falamos então do local onde moramos e pedimos que eles falem também. 
Representante da CRE - A escola está envolvida e isso nos deixa felizes, por perceber a forma como os professores investem nas crianças. É a tal história do carinho que os alunos recebem e nós damos.

Os professores demonstram tanto a preocupação com as necessidades relativas à situação de carência afetiva dos alunos quanto à necessidade de implementar atividades alternativas que possam despertar o interesse de seus alunos para os conteúdos sistemáticos. Nessa segunda fase da pesquisa, na observação das reuniões, tanto nos Centros de Estudos quanto nos Conselhos de Classe, em diferentes momentos, a atenção e o cuidado dos professores ficaram evidentes. Em algumas falas, pode-se observar a preocupação desses profissionais:

P9 - É necessário compreender a necessidade dos alunos. Uma memória que precisa ser atendida, os trabalhos devem ser diversificados, deve haver mais agitação, dinamismo.

P3 - Queria pegar os livros para ajudá-los. Se tiverem repetido, vamos tentar ler. (...) Gostaram do livro de história e conseguiram ler alguma coisa (...) Fazem de dois jeitos, querem ler e desenhar a história. Pude perceber que melhoraram muito (depoimento da professora responsável pela sala de leitura).

P6 - Eu aproveito muito a história. Eu sou economista e acho que posso aproveitar a história. Agora estou realizando atividades da Matemática, mas sempre ligando a outros conteúdos.

Durante a reunião do Centro de Estudos, com a presença da representante do CRE, foi observada a discussão sobre os projetos da SME, entre os quais o da sala de leitura e os projetos de aceleração. Percebeu-se a adesão e empenho dos professores das unidades observadas no trabalho que estava sendo desenvolvido. Alguns se pronunciaram a respeito:

P4 - O objetivo comum aos projetos é reduzir os índices de repetência e evasão, mas tratando-se de melhorar a qualidade de aprendizagem, cabe maior apoio ao trabalho do professor, com a atenção de outros profissionais na escola, garantindo que o professor atue como avaliador no cotidiano do aluno e com segurança naquilo que faz.

P11 - Há um expectativa de excelentes resultados, no entanto na primeira série não ocorreram os resultados positivos esperados.

P13 - Seria necessário a elaboração e participação dos professores, trabalhando em oficinas; os materiais e textos deveriam ser distribuidos para os diferentes níveis. 


\section{Análise e interpretação dos dados coletados na segunda etapa}

Na segunda etapa, o estudo teve caraterísticas do estudo etnográfico (André, 1995), restringindo-se a apenas uma escola municipal da 1. ${ }^{\mathrm{a}} \mathrm{CRE}$, denominada neste relato escola D. Foram tomadas as providências burocráticas junto à SME, obtendo-se o apoio de duas bolsistas de iniciação científica. $\mathrm{O}$ estudo referiu-se especificamente à análise das modalidades de avaliação implementadas no Ensino Fundamental, no contexto dos Parâmetros Curriculares Nacionais - PCNs e à contribuição das modalidades de avaliar do Ensino Fundamental para o desenvolvimento da autonomia do sujeito. Foram efetivadas de forma periódica observações de classes e dos espaços escolares durante atividades formais e informais para alunos e professores.

Dos procedimentos adotados no primeiro momento da segunda etapa foram obtidos dados junto aos alunos da quarta série, que revelaram alguns dos pontos de vista e preferências dos entrevistados sobre a avaliação, que podem ser constatados nas falas a seguir:

P1 - O professor avalia a prova, o comportamento, as tarefas de casa, a limpeza e organização dos cadernos e as faltas.

P2 - A avaliação não é dada apenas pela prova, além dela é considerado o comportamento, a limpeza, os cadernos, a organização.

P3 - As pesquisas são melhores que as provas. Aprendo mais fazendo pesquisa, não precisa ter prova. Aprendi muito com a Feira de Ciências; prefiro a pesquisa individual. Todos os dias minha mãe olha os cadernos. Quando ela vê alguma coisa errada, ela pede para fazer tudo de novo. Falou para fazer novamente todas as questões erradas da prova. Ajuda bastante. Se ela não fizesse isso eu não ia render tanto na, escola.

P4 - Aprendo melhor fazendo pesquisa individual; eu não fico nervosa na hora da prova; precisa ter mais trabalho que prova; minha mãe cobra os estudos. Gostei muito da Feira de Ciências porque aprendi tudo na prática. Eu gosto de fazer teste, às vezes a professora dá teste surpresa.

P6 - Prefiro o trabalho individual, eu aprendo mais pesquisando. A minha mãe sempre ajuda. Quando tiro nota baixa, tira o videogame. Fico nervoso na hora da prova e sempre esqueço alguma coisa.

P7 - Prefiro o trabalho em grupo, aprendo mais pesquisando. Quando estudo para prova esqueço e quando faço o trabalho não esqueço. A mãe ajuda, explica, depois que chega do trabalho pergunta. Eu pretendo ser advogada.

Essas falas mostram, por um lado, que os alunos compreendem que a prova não é a única forma de avaliar e, por outro, discordam quanto às suas preferências em relação às formas de avaliar e se expressam acerca da relação entre aprendizagem e avaliação. Pelas falas de alguns dos 
participantes pode-se também interpretar que as pesquisas individuais ou em grupo, solicitadas pelas professoras, conferem possibilidades de iniciativa, o que pode sinalizar para o desenvolvimento da autonomia do aluno. Os depoimentos seguintes explicam qual o significado dos conceitos dados pela professora:

P8 - Os conceitos são PS, S, EP. O PS significa que o aluno é muito bom; o S que o aluno está bem e o EP que o aluno está muito mal.

P9 - Para passar de ano tem que tirar PS em todos os bimestres. Se tirar PS em três bimestres e EP no último bimestre fica em recuperação.

Quanto às atividades desenvolvidas pelos professores, os alunos entrevistados assim se pronunciam:

P10 - As atividades são boas porque quando estudamos para a prova estudamos muito para aquela prova e depois que esquecemos o que estudáramos. Fazendo as atividades relacionadas às matérias escolares gravamos melhor.

P11 - Preferimos as atividades não-padronizadas.

P12 - Seria melhor que só tivesse uma prova no final do ano.

P13 - Gostariam que os professores substituíssem o ensino padronizado, fazendo atividades diferentes.

P14 - Gostaríamos de aprender matemática, por exemplo, preparando um bolo e aprender com as medidas usadas para preparar o bolo; o professor devia passar filmes, passar jogos, porque assim gravamos melhor.

P15 - As feiras de Ciências são muito boas, porque aprendemos na prática o que já escutamos na teoria; gostamos muito de fazer experiências.

P16 - Gostamos de prova com consulta e em dupla.

Alguns desses depoimentos expressam as preferências dos alunos por um ensino diferente, com atividades concretas, mais criativas, menos padronizadas, como, por exemplo, os jogos, os filmes e também as Feiras de Ciências, nas quais aparecem oportunidades de participação e atividades autônomas, nas quais os alunos decidem o que vão realizar e como participar.

No segundo momento dessa etapa, pelos depoimentos dos professores de classes diversas, isto é, ciclos escolares, classes de aceleração e classes regulares, reunidos nos Conselhos de Classe, os seguintes temas emergiram após a análise dos dados coletados: (a) a complexidade do processo de avaliar; (b) necessidade de atendimento diferenciado aos alunos; (c) critérios favoráveis à aprovação dos alunos às séries seguintes; (d) valorização da disciplina no cotidiano da sala de aula; e (e) sinalização de problemas familiares graves. 
Quanto ao tema (a) complexidade do processo de avaliar, percebese que o professor necessita, ainda, ser orientado para as novas modalidades de avaliação, que enfatizam a observação de todos os alunos continuamente para garantir um avaliação global, para a elaboração de um relatório, no tocante aos ciclos escolares e às classes de aceleração. As seguintes expressões dos professores podem ser citadas:

$\operatorname{Pr} 5$ - A avaliação deve ser um processo coerente, que articule desempenho, competência e freqüência. É um momento difícil: avaliar como um todo, considerando o contexto da escola municipal e a proposta de aceleração $1 e$ 2.

Pr6 - A turma tem um bom desempenho. Não é o que esperava, no entanto o comportamento e a freqüência são bons, menos a aluna nova que veio da Bahia: não tinha condições de render, deixou de freqüentar a escola. Há três alunos que ainda não sei como avaliar, tenho dúvidas; têm limitações de saúde e sociais.

Pr5 - São alunos com idade fora da série, há meninos com 18 anos; por exemplo o Lt. escreve e é emocionalmente frágil. Serão todos aprovados.

Pr8 - Os alunos melhoraram no comportamento, mas não na aprendizagem. Três estão bem preparados para a quinta série; têm autonomia. Por exemplo MR. apesar de ter faltado muito conseguiu alcançar os objetivos. Muitos são desinteressados; $\mathrm{Mq}$ não entendia as ordens. Alguns devem ir para a terceira série, outros para a quarta.

No que se refere ao tema (b) necessidade de atendimento diferenciado aos alunos, os professores consideram que há emergência de atender os alunos de acordo com suas diferenças - faltas, agitação, problemas de vista, auto-estima negativa - embora nem sempre consigam pensar em alternativas que possam despertar o interesse de todos os alunos. Destacam-se as seguintes falas dos professores sobre essa questão:

$\operatorname{Pr} 9$ - Na minha turma não há alunos faltosos. Há falta em geral, cada dia tem um número de alunos que faltam. Quando estão muito agitados faço atividades diferentes. Há duas crianças com problemas de audição, há algumas crianças agressivas. O caso mais sério é o da AL. Tem uma aparência diferente, parece estar num outro mundo; gosta de danças, não se senta...

Pr13 - Gostei muito do trabalho realizado, embora não consiga fazer um trabalho diferenciado. Tive quatro alunos que não se alfabetizaram. Agradeço a Sv que me ajudou muito. Gostaria de utilizar um outro método. $\mathrm{Cl}$ falta muito; Ct. vem à aula, está alfabetizado; Mc tem muita dificuldade, sem iniciativa, é muito quieta; Al tem bloqueios em muitos aspectos, não consegue escrever o nome inteiro; Pd é mimado, um bebezão. Alguns não estão totalmente alfabetizados; outros não alcançaram os objetivos finais. 
Pr16 - Há várias crianças na minha turma que já sabem ler e escrever. Não se pode juntar crianças da aceleração 1 - que não são alfabetizadas - com as crianças de classes regulares, as idades são diferentes e a metodologia também, prevista para os que não se alfabetizaram em classes regulares

Em relação ao tema (c) critérios favoráveis à aprovação dos alunos às séries seguintes, questão que constitui um aspecto crítico, visto que o aluno deve ser aprovado de acordo com suas possibilidades, que são freqüentemente abaixo do desejável para a série em que se encontra, é apontada pelos professores como fator desencadeador da situação crítica em que se acha a escola atualmente. Sobre essa questão destacam-se as seguintes falas:

Pr5 - É a última oportunidade para a promoção ou repetência, através de módulos com objetivos para atender às diferenças individuais: é direito do aluno. Os pais, em caso de não ser dada essa oportunidade poderão recorrer ao Conselho Nacional de Educação. O professor deverá deixar o módulo preparado. Em fevereiro haverá prova para se verificar o rendimento do aluno, só aí poderá ser definida a reprovação. (Resolução 684)

Pr15 - Cinco alunos poderão cursar a quinta série. Houve algum aproveitamento. Os critérios adotados foram a ênfase na leitura e na escrita. Alguns têm dificuldades no conteúdo de Matemática, mas entendem a situação problemática. $50 \%$ deverão ficar na terceira série. $O$ $\mathrm{Br}$ não deu conta do programa de aceleração. Consegue produzir junto com outros. A Ld tem obstáculos de natureza cognitiva. O Ad pode ir para a quarta série. A Jl nunca pisou na escola, veio direto para a classe de aceleração

O tema (d) valorização da disciplina no cotidiano da sala de aula relaciona-se com o valor que é atribuído à disciplina para que os alunos aprendam. A esse respeito pode ser transcrita a fala seguinte:

Pr17 - Foi falado que às vezes as professoras menosprezam o potencial dos alunos; quando o pai confia no seu trabalho ele vai se esforçar junto com o professor e o aluno. Devemos exigir dos alunos seriedade e compromisso; espero que o aluno seja disciplinado; a disciplina é o ponto de partida; acho que isso facilita o meu trabalho; os pais estão muito empenhados; os alunos melhoraram a frequiência; quatro crianças apenas não escrevem nem o nome, não lêem; Cl escreve o nome e identifica os números.

O tema (e) sinalização de problemas familiares graves refere-se aos obstáculos que desvelam as próprias causas das diferenças entre seus alunos - famílias divididas, famílias ausentes, famílias "doentes", famílias 
sem recursos. Entre os inúmeros relatados podem ser destacadas as seguintes falas:

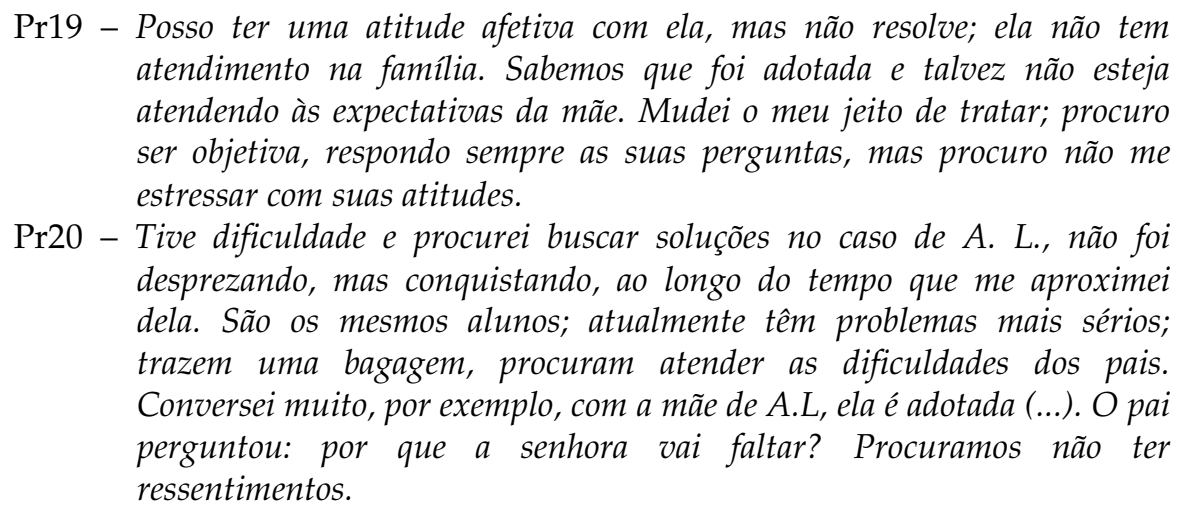

A análise prévia desses temas sinaliza para uma teia de significados na fala dos dirigentes e professores da escola observada: os participantes entendem a complexidade do processo de avaliar que deve levar em conta a diversidade dos alunos de suas classes, com a necessidade de um atendimento diferenciado. Apontam, no entanto, as dificuldades de lidar com as diferenças, no contexto das novas modalidades de avaliar que apresentam critérios favoráveis à aprovação; nesse contexto, compreendem a disciplina como um fator importante na sala de aula e como nem sempre conseguem um comportamento favorável, apelam para as famílias, encontrando problemas graves, tanto na dimensão social, quanto afetivoemocional, para a solução dos problemas detectados.

Os temas emergentes nessa análise não apresentam explicitamente a questão da autonomia que se configura como aspecto fundamental nessa etapa da investigação. Embora sinalize para a falta da autonomia dos alunos, que devem se submeter a formas padronizadas de transmissão de conteúdos e de avaliação, os professores devem ter uma atitude disciplinada, entre outros aspectos apontados, como a necessidade de atender à diversidade dos alunos, o que configura o respeito às suas características individuais.

A complexa teia de significados apresenta questões conflitantes para os professores que devem lidar com seus alunos, atendendo, ao mesmo tempo, aos novos critérios de avaliação que consideram os indicadores de autonomia a serem trabalhados pelos professores, e às exigências explícitas nas propostas dos PCNs, com orientações didático-metodológicas relevantes para a prática dos professores. Nos documentos impressos, o 
discurso assinala aspectos significativos relacionados à diversidade dos alunos, à autonomia e ao espaço escolar, entre outros.

É válido sinalizar que os professores expressam suas dificuldades nas práticas pedagógicas, algumas vezes distantes das orientações preconizadas nos documentos oficiais e no cumprimento de suas responsabilidades frente ao atendimento das exigências burocráticoadministrativas. Basta lembrar os instrumentos de avaliação que devem ser analisados e preenchidos a cada trimestre pelos professores, assinalando categorias relativas à autonomia dos alunos, elencados a seguir: I Trabalha com autonomia e compreensão; II - Trabalha com relativa autonomia e desenvolve compreensão; III - Necessita de ajuda constante para trabalhar e compreender; e IV - Apresenta, ainda, dificuldades, mesmo com ajuda constante.

As observações, no decorrer da investigação, mostraram a resistência velada de alguns participantes do estudo, decorrente das múltiplas solicitações tanto das orientações enviadas pela SME quanto dos que dirigem as instituições escolares.

\section{BREVES CONSIDERAÇÕES E CONCLUSÕES}

Tendo em vista os objetivos da primeira etapa, voltada para as relações entre aprendizagem e avaliação, e dos resultados das avaliações sobre o processo de desenvolvimento e aprendizagem do sujeito, pode-se dizer que, em sua maioria, os professores-participantes expressaram em suas falas que compreendem a inter-relação entre o processo de aprender e o de avaliar, assumindo procedimentos que enfatizam o processo e não os resultados obtidos, embora nem sempre tenham clareza na aplicação de modalidades inovadoras de avaliação.

Na segunda etapa, considerando os objetivos delineados referentes à análise das modalidades de avaliação implementadas no Ensino Fundamental e da contribuição dessas modalidades para o desenvolvimento da autonomia do sujeito, as observações e entrevistas realizadas ao longo da pesquisa mostraram que, embora a SME/RJ tenha assumido o compromisso na implantação dos programas oficiais, gerados pelas orientações dos PCNs, nem sempre tem conseguido investir o suficiente para a qualificação e adesão dos professores às inovações instituídas. Pelas falas dos alunos pode-se dizer que entendem que podem aprender de diferentes formas e que a avaliação é realizada por meio de vários instrumentos. Considerando as idéias e conceitos inovadores relacionados ao processo de avaliar, pôde-se observar que os professores 
ainda encontram dificuldades em analisar o desempenho dos alunos, a partir dos instrumentos que avaliam o seu nível de autonomia, visto que não abandonaram inteiramente as formas tradicionais de avaliar, os testes e as provas.

A presença da pesquisadora nas escolas investigadas possibilitou algumas considerações sobre o momento atual das unidades escolares: há um empenho indiscutível da direção - entre as quais as diretoras, as diretoras adjuntas e as coordenadoras pedagógicas - para o êxito das atividades que são desenvolvidas com seriedade, respeito à equipe de professores, compromisso com a diversidade dos alunos, busca de soluções coletivas, estímulo ao desenvolvimento dos alunos em inúmeras iniciativas, embora se reconheça, em diferentes momentos, os entraves relativos à falta de alguns materiais indispensáveis a atividades fundamentais do cotidiano escolar, como, por exemplo, para as atividades desenvolvidas pelas classes de aceleração.

A equipe de professores está identificada com a proposta do ensino público, entende o contexto sociocultural dos alunos, preocupa-se com os conteúdos necessários para a construção dos saberes dos alunos, embora tenha certa preocupação com comportamentos que considera inadequados para a sala de aula e se expresse sobre a ausência de uma estrutura familiar que respalde a mudança desses comportamentos e a necessidade de decisões mais rígidas para determinados alunos.

Como uma das conclusões do estudo pode-se afirmar que as formas como são instituídas as propostas oficiais, sem que os professores possam se apropriar das competências necessárias à implementação das mesmas, é um dos obstáculos para o êxito do processo. Outra conclusão diz respeito à realidade em que se inserem as escolas que traz resquícios de significados e práticas sociais emergentes de fases anteriores, embora já se pressintam possibilidades de mudanças caminhando para os novos rumos do processo de avaliar que, no entanto, exigem do educador a continuidade de sua ação na busca de soluções assumidas coletivamente com a comunidade escolar, o que tem se constituído em desafios significativos para os professores do ensino fundamental.

\section{REFERÊNCIAS BIBLIOGRÁFICAS}

ANDRÉ, Marli Eliza D. A. de. Etnografia da Prática Escolar. São Paulo: Papirus, 1995. 
BRASIL. Ministério da Educação e do Desporto. Introdução. Secretaria de Educação Fundamental. Rio de Janeiro: DP\&A, 2000.

BRASIL. Parâmetros Curriculares Nacionais. Secretaria de Educação Fundamental. Rio de Janeiro: DP\&A, 2000.

ESTEBAN, Maria Teresa. O que sabe quem erra? Reflexões sobre avaliação e fracasso escolar. Rio de Janeiro: DP\&A, 2000.

FERNANDEZ, Alicia. A Inteligência aprisionada: abordagem psicopedagógica clínica da criança e de sua família. Porto Alegre: Artes Médicas, 1990.

FORQUIN, J. C. Escola e cultura. Porto Alegre: Artes Médicas, 1993.

FREIRE, Paulo. Pedagogia da Autonomia. São Paulo: Paz e Terra, 2000.

LUCKESI, Cipriano. Avaliação da aprendizagem escolar. São Paulo: Cortez, 1996.

PATTO, Maria Helena. A produção do fracasso escolar. São Paulo: T.A. Queiroz, 1993.

PERRENOUD, Phillipe. Avaliação: da excelência à regulação das aprendizagens - entre duas lógicas. Porto Alegre: Artes Médicas, 1999

PERRENOUD, Phillipe. Formação contínua e obrigatoriedade de competências na profissão de professor. In: IDÉIAS: sistemas de avaliação educacional. São Paulo: FDE, Diretoria de Projetos Especiais, 1998

PERRENOUD, Phillipe. Novas competências para ensinar. Porto Alegre: ARTMED, 2000.

RIO DE JANEIRO (município). Secretaria Municipal de Educação. Multieducação. Proposta curricular, 1995. 